\title{
Extensión de Beneficios Sociales para Abogados
}

\author{
por el Dr. ALBERTO D'ANGELO GEREDA.
}

Es un anhelo largamente acariciado por los abogados que prestan servicios a empresas de toda clase y que desempeñan labores profesionales en ciertas condiciones especiales, que se les comprenda dentro de los beneficios sociales acordados a los empleados.

Sin embargo, se ha objetado este justo deseo, afirmándose, que no es posible considerar al abogado en calidad de empleado. Mas esta crítica confunde los conceptos y no enfoca la aspiración de los abogados en su verdadero lugar. En efecto, no es que se considere al abogado en calidad de empleado lo que se pretende, pues el primero por su título profesional y la naturaleza de su labor tiene su categoría propia; lo que se quiere, es que el abogado goce de los beneficios sociales que las leyes han concedido a los empleados, por el mismo fundamento que éstos, ya que, conjuntamente ambos, colaboran en los rendimientos económicos de las empresas a las que prestan sus servicios.

Por otra parte, se ha dicho que no es conveniente extender los beneficios sociales a los abogados, porque perderian su independencia al defender los derechos sociales de los empleados, pero como muy bien se ha contestado, los abogados por tener derechos similares a los empleados no perderían su formación jurídica, ni menos su libertad de conciencia.

Se ha creido encontrar un problema, en torno a la multiplicidad de prestaciones profesionales, para el pago de los beneficios sociales. Pero ya el Derecho de Trabajo se ha encargado de resolver estas aparentes dificultades, en otras actividades laborales, como las de los contadores públicos. trabajadores marítimos o de minas, ets.

Es fenómeno de carácter mundial, el empuje que se advierte en todos los países por establecer bases firmes de justicia social y de seguridad económica para todos, suprimiéndose los privilegios de grupos o personas. De ahí, que en las legislaciones de otros países ya estén comprendidos los abogados en los beneficios sociales o amparados por leyes especiales de seguridad social. Basta con citar en Sud-Ámérica a la Ärgentina, Chile y Bolivia, entre otros. 
En nuestra legislación y jurisprudencia existen tímidas tentativas para extender los beneficios sociales a los profesionaies. Así, tenemos la Resolución Suprema de 5 de Abril de 1929, que comprendió en el art. $1^{\circ}$ del Reglamento de la Ley $\mathrm{N}^{\circ} 4916$, a los profesionales en general, que prestan servicios a empresas comerciales e industriales y demás a que se contrae la Ley del Empleado; el Decreto Supremo de 27 de Julio de 1949, que en su art. $7^{\circ}$ acordó una bonificación mensual a los profesionales, siempre que laborasen en los centros de trabajo. La Resolución Ministerial de 7 de $\mathrm{Fe}-$ brero de 1955, en cuyo art. $3^{\circ}$ consideró a los profesionales que prestan servicios por horas en las escalas de aumento a los sueldos a que se refiere el art. $1^{\circ}$ del Decreto Supremo de 2 de febrero del mismo año. (1) Lamentablemente, dichas disposiciones, por su imprecisión con referencias a los profesionaies, por tratarse de beneficios especiales concedidos a los empleados y sobre todo, por no existir una ley expresa que comprenda a los profesionales dentro de los beneficios sociales, no fueron cumplidas por la mayoría de las empresas.

La Corte Suprema ha protegido dos demandas de profesionales que solicitaban se les considerase comprendidos en los beneficios sociales de los empleados, expidiendo la Ejecutoria Suprema de 14 de Enero de 1942, en la causa seguida por el doctor Juan Cipriani con la Empresa del Ferrocarril Central, en la que declara que el profesional con consultorio abierto, que dedica mós de cuatro horas diarias a atender a los empleados y obreros de una empresa está amparado por la ley del empleado, ya que son notas características de estos servicios: subordinación contractual, continuidad de relaciones y remuneración mensual tija; el mismo criterio ha informado la Ejecutoria Suprema de 6 de Junio de 1949, que dispuso el pago al Ingeniero Alberto Alexander de las indemnizaciones por tiempo de servicios, estipuIadas en la ley del empleado, no obstante el hecho, acreditado por el Banco Central Hipotecario del Perú, de no haber trabajado el profesional demandante durante horas continuadas en la oficina de la empresa. Esta ejecutoria consideró que el hecho de prestar servicios continuados en o fuera de la oficina con sujeción a un sueldo fijo y abarcando presuntivamente en el desempeño de la correspondiente actividad un apreciable espacio de tiempo cada día, sitúa al profesional en el marco del empleado y lo hace acreedor a todos los beneficios sociales estatuídos en la ley.

Sin embargo, conjura contra el criterio expuesto en la última ejecutoria, favorabie a los derechos de los profesionales no sujetos $\alpha$ horario fijo, el ort. $21^{\circ}$ de la Ley 6871 - no modificado por la Ley $N^{\circ}$ 10473- conforme al cual los contadores que trabajan por horas serón amparados por las leyes del empleado, siempre que laboren un mínimo de tres horas en la misma empresa.

El abogado al servicio de las empresas, realiza su función con inde-

(1) El Decreto Supremo de 13 de junio de 1958, complementario $Y$ reglamentario del Decreto Supremo No 10 de 29 de mayo de 1958, sobre aumento de sueldos a los empleados privados, en su art. $6^{\circ}$ considera a los profesionales. 
pendencia de las directivas que creyeran o quisieran imponer los personeros de las mismas, en la esfera de la aplicación de sus conocimientos técnicos y de sus consejos profesionales. No obstante, esta elevada independencia, no lo sustrae de la disciplina de la empresa, en cuanto al desenvolvimiento diario de su labor profesional, cuya ejecución y control se encuentra a cargo de los funcionarios que la administran, así como a la obligación de concurrir a la oficina de la empresa cuando se ha convenido esta condición. En este sentido, todos los profesionales de una empresa en cuanto a la ejecución del trabajo, estón subordinados a ella, en razón de sus fines, sin desmedro de su noble función, afiliados al rango de colaboradores cotidianos, y por tanto deben ser amparados por los beneficios sociales que las leyes acuerdan a sus servidores.

En el año de 1950, siendo Decano del Colegio de Abogados de Lima, el doctor Manuel Cisneros Sánchez, esta Institución acogió el sentir de numerosos miembros de nuestra Orden y realizó gestiones ante el Ministerio de Trabajo, para que se reconociesen los derechos sociales a los abogados. Infortunadamente, tales gestiones no dieron resultados definitivos, pero merecieron la acogida del Ministro de Trabajo de entonces, $\alpha$ cuya recomen. dación se consignaron en el Anteproyecto del Código de Trabajo los artículos $21^{\circ}$ y $85^{\circ}$, que incluyen en los beneficios que corresponden a los empleados a los profesionales, siempre que laboren en el centro de trabajo y reciban por sus servicios sueldo $u$ honorario fijo, sin que les sea exigible los requisitos de la asistencia exclusiva y el tiempo horario mínimo para alcanzar el derecho al goce indemnizatorio.

E1 23 de Agosto de 1950, los diputados por Huancavelica doctores Raúl Martínez Zuzunaga y José Valdivia Manchego, presentaron a su Cámara, un proyecto de ley, que incluye en los beneficios de la Ley 4916, sus ampliatorias, modificaciones y conexas,, a los abogados que presten servicios en forma continuada a las empresas, "en el propio centro de trabajo o fuera de él; con o sin horario establecido, y siempre que la remuneración que perciban sea fija o permanente". Este proyecto de ley fue aprobado en la Cámara de Diputados y se encuentra pendiente de conocimiento de la Cómara de Senadores.

En el Congreso Internacional de Juristas, reunido en Lima del 8 al 18 de Diciembre de 1951, en atención a una fundamentada ponencia presentada a la Comisión de Derecho del Trabajo, por los doctores Guillermo Gonzáles Rosales y Raúl Martínez Zuzunaga, sobre la extensión de los beneficios sociales a las profesiones liberales, recayó la resolución siguiente: "Recomendar que la legislación social otorgue los bēneficios derivados del Contrato de empleo privado a los Abogados, Médicos, Odontólogos, Farmacéuticos, Ingenieros, Veterinarios y Obstetrices, que trabajen continuamente al servicio de empresas industriales o comerciales, con remuneración fija, con o sin horario".

En vista del interés que provocó dicho proyecto, la Junta Directiva del Colegio de Abogados de Lima, que presidía el doctor José León Barandiarán, convocó a sesión de Junta General Extraordinaria, con fecha 15 de Octubre de 1954, a fin de conocer la opinión de los asociados. El resultado 
de dicha sesión puso de manifiesto el entusíasmo con que fué recibido el mencionado proyecto, el que fué aprobado por gran mayoría de votos.

El Anteproyecto de la Ley Orgánica del Poder Judicial, formulado por la Comisión nombrada por Resolución Suprema de 19 de Abril de 1952, contiene una disposición que concede beneficios sociales a los Abogados, bastando para ello, que perciban de sus clientes un honorario periódico, (Tít. XXIII, art. $\left.448^{\circ}\right)$.

En la Primera Convención Regional de Colegios de Ábogados del Norte, celebrado en Trujillo, del 25 al 29 de Diciembre de 1954, se abordó el tema de la Seguridad Social del Abogado, aprobándose la conclusión siguiente:

"10--Expresar su adhesión al proyecto de ley aprobado en la Cámara de Diputados, que comprende en la Ley $\mathrm{N}^{\circ} 4916$, sus ampliatorias, modificatorias y conexas a los Abogados y demás profesionales que indica, que presten servicios en forma continuada, en empresas industriales o comerciales o en instituciones sostenidas o dependientes de éstas, en el propio centro de trabajo o fuera de él, con o sin horario establecido, y siempre que la remuneración que perciban sea fija y permanente".

El Primer Congreso Nacional de Ābogados, que se reunió en Lima, del 17 al 22 de Octubre de 1955, consideró en su Temario: "I.-Seguridad Social del Abogado.- $\alpha$ ).--Beneficios Sociales para el Abogado.-_" La Primera Comisión que tuvo a su cargo el estudio de las ponencias sobre "Beneficios Sociales para el Ábogado", presentó el proyecto de resolución siguiente:

"El Primer Congreso Nacional de Abogados del Perú, acuerda:

1.-Recomendar la extensión de los beneficios sociales concedidos por la Ley 4916, sus ampliatorias y modificaciones a los Abogados que prestan servicios profesionales a las empresas, con 0 sin horario, en el centro de trabajo o fuera de él, a uno o más empleadores con o sin remuneración fija.

$2^{\circ}$-Recomendar al Colegio de Abogados de Lima, que gestione la extensión de beneficios sociales a los Abogados en los términos contenidos en el punto precedente".

En Sesión Plenaria del Primer Congreso Nacional de Abogados del Perú realizado el 19 de Octubre de 1955, fué aprobada la Resolución anterior.

En el año 1956, en cumplimiento de la recomendación del Primer Congreso Nacional de Abogados del Perú, por acuerdo de la Junta Directiva del Colegio de Abogados de Lima, su Decano Doctor Manual G. Abastos, con fecha 3 de Setiembre, ofició a la Cámara de Senadores, a fin de que amparase el proyecto que reconoce beneficios sociales a los Abogados y, por encargo de la misma Junta Directiva, el mencionado Decano en compañía del Diputado Cuarto Felipe Aparicio, visitó al Presidente del Senado, para pedirle que pusiera en la Orden del Día el proyecto aprobado en Diputados, que otorga beneficios sociales a los Ảbogados. Aunque por oficio de 10 de Setiembre de 1956 y verbalmente, se obtuvo una respuesta 
alentadora, la Cámara Alta terminó sus sesiones sin ocuparse del asunto. Toca a la nueva Junta Directiva del Colegio de Abogados de Lima, insistir en la petición y solicitar el apoyo de los Senadores que son miembros de la Orden, quienes, estamos seguros no podrán negarlo, ya que se trata de un justo y humano beneficio en favor de sus propios colegas.

En mi modesta opinión, tal extensión de beneficios sociales debe otor. garse, siempre que el abogado al servicio de las empresas reuna las condiciones siguientes:

1.-Remuneración permanente y fija.

2 - Continuidad en la prestación de servicios, de modo que no se trate de prestaciones eventuales, que configuran los contratos de locación de servicios o de obras, previstos en el Código Civil.

$3^{\circ}$-Libertad de trabajar en las oficinas de la empresa o fuera de ellas.

No debe tenerse en cuenta que el horario sea continuo o determinado número de horas de labor, pues dada la naturaleza del trabajo del abogado estas condiciones no son indispensables, ya que muchas veces se lleva a su casa o estudio los asuntos encomendados por la empresa, por insuficiencia del tiempo convenido con ésta o para resolverlos con mayor tranquilidad y consultando libros que no obran en el centro de trabajo. A este respecto debe tenerse presente, que el trabajo a domicilio ya está reconocido en el Derecho de Trabajo.

Como hemos visto, Congresos Internacionales, Nacionales y Regionales de Abogados, así como la legislación y Jurisprudencia Nacional y Extranjera, se han pronunciado en el sentido de extender los beneficios sociales a los abogados, en razón de que no hay motivo alguno, para que este numeroso grupo profesional, se encuentre al margen de las leyes de protección social, que tienden a amparar todas las actividades humanas.

No obstante que nuestro país es de avanzada legislación social, en cuanto se refiere a los profesionales, no se ha puesto a la altura de otros países, a pesar de los antecedentes que hemos expuesto y de la abrumadora corriente a favor de conceder beneficios sociales a los abogados.

Corresponde a la Cómara de Senadores y al Ejecutivo, la aprobación y promulgación del proyecto de ley, concesorio de dichos beneficios, aprobado ya en la Cámara de Diputados, a fin de no reiardar el justo anhelo de los abogados. 